\title{
Unintentional injuries among children aged 1-5 years: understanding the burden, risk factors and severity in urban slums of southern India
}

Srujan Lam Sharma ${ }^{1 \dagger}$, Samarasimha Reddy $N^{2 \dagger}$, Karthikeyan Ramanujam², Mats Steffi Jennifer ${ }^{2}$, Annai Gunasekaran ${ }^{2}$, Anuradha Rose ${ }^{3}$, Sushil Mathew John ${ }^{4}$, Anuradha Bose ${ }^{3}$ and Venkata Raghava Mohan ${ }^{3^{*}}$ (i)

\begin{abstract}
Background: Globally, 5.82 million deaths occurred among children under the age of five years in 2015 and injury specific mortality rate was 73 per 100,000 population. In India, injury specific mortality rate is around 2.1 per 1000 live births contributing to $4 \%$ of the total under 5 mortality rate. This study aims to estimate the burden and understand factors associated with unintentional injuries among children aged 1-5 years residing in urban slums of Vellore, southern India. We also attempted to assess the hazards posed by the living environment of these children and study their association with unintentional injury patterns.

Methods: This cross-sectional study was conducted in eight urban slums of Vellore, southern India and primary caregivers of children aged 1-5 years were interviewed with a questionnaire to obtain the details of injuries sustained in the past three months. Environmental hazard risk assessment was conducted at places frequented by these children and their scores calculated. Baseline prevalence and incidence rates of unintentional injuries were estimated. Multivariate logistic regression and poisson regression analysis were performed to examine factors associated with unintentional injuries and repeated injuries respectively. Association between environmental hazard risk and unintentional injuries was estimated.
\end{abstract}

Results: Prevalence of unintentional injuries was 39.1\% (95\% Cl 35.4-42.9\%) and incidence rate was 16.5 (95\% Cl 14.7-18.3) per 100 child months $(N=662)$. Bivariate analysis revealed that children of working mothers $(O R$ 1.48; 1.01-2.18) and children from overcrowded families (OR 1.78; 1.22-2.60) had increased odds of sustaining unintentional injuries. Multivariate regression analysis revealed that children from overcrowded families had increased odds of sustaining unintentional injuries (AOR 1.66, 95\% Cl 1.14-2.41). Boys (IRR 1.33, 95\% Cl 1.07-1.66) and children from overcrowded families (IRR 1.50; 1.14-1.98) were at increased risk of having repeated injuries. There is an increase in incidence rate of injuries with an increased environmental hazard risk, although not statistically significant.

Conclusions: The burden of unintentional injuries was very high among study children when compared to studies in other urban slums in India. Environment plays an important role in the epidemiology of unintentional injuries; providing safe play environment and adequate supervision of children is important to reduce its burden.

Keywords: Unintentional injuries, Environmental hazards, Hazard score, Under-five children, Urban slums, India

\footnotetext{
*Correspondence: venkat@cmcvellore.ac.in

†Srujan Lam Sharma and Samarasimha Reddy N contributed equally to this

work.

${ }^{3}$ Department of Community Health, Christian Medical College, Vellore, Tamil

Nadu 632004, India

Full list of author information is available at the end of the article
} 


\section{Background}

Globally, 5.82 million deaths occurred among children under the age of five years in 2015. (Global Burden of Disease Child and Adolescent Health Collaboration et al. 2017). The injury specific mortality rate in the under five age group was 73 per 100,000 population and 3654 years of life were lost per 100,000 population (WHO 2015). Among children aged 1-5 years, injuries are the leading cause of death in the developed world (Sminkey 2008). Additionally, there is an unequal distribution between the developed and the developing world, with the mortality rate from unintentional injuries in developing countries being nearly twice that of the developed world (Chandran et al. 2010). According to the World Health Organization (WHO), up to 50\% of the children presenting to a hospital with unintentional injuries are left with some form of disability (Peden et al. 2008). More than $95 \%$ of all the injury deaths in children occur in the Low and Middle Income countries; children in Southeast Asia have the second highest rates $(49 / 100,000)$ of unintentional injuries in the world (Peden et al. 2008).

According to World Health Statistics 2015, overall under 5 mortality rate (U5MR) in India in 2013 is 52.7 per 1000 live births and injury specific mortality rate is around 2.1 per 1000 live births contributing to $4 \%$ of the total U5MR (WHO 2015). In a national survey based on verbal autopsy, the mortality rate related to injuries among children under 5 years was 302 per 100,000 live births (Jagnoor et al. 2011). Studies from rural Andhra Pradesh and Tamil Nadu have documented injury rates of 307 and 342 per 1000 child-years respectively (Nirgude et al. 2012; Sivamani et al. 2009). Unintentional injuries thus lead to substantial morbidity and mortality in children younger than five years of age in India. Children under the age of one have different patterns of injuries with most injury-related deaths attributed to suffocation as a result of an unsafe sleeping environment (Borse et al. 2008; Imamura et al. 2012). At the age of 1-5 years, children start to move more independently and this increases their risk of injury. A multinational study conducted in developing nations found that children aged 1-5 years sustain injuries with the most long-term consequences with high mortality rates (Hyder et al. 2009; Morrongiello and Matheis 2007).

In India, unplanned urbanization and rise in informal settlements are leading to an increase in urban slums thus leading to high population density and overcrowding (Bandyopadhyay and Agrawal 2013; Tripathi 2015). Lack of spaces in Indian towns and cities due to rapid urbanization has increased the environmental hazards and as a consequence, injuries of all types including unintentional injuries among younger age groups have increased (Naeini et al. 2011; Nambiar et al. 2017). In India, since most under five deaths still continue to be due to infectious causes, more emphasis is placed on vaccine-preventable diseases and there is a lack of policy focus and planning directed at unintentional injuries, a preventable source of significant morbidity and mortality (Fadel et al. 2017). With the paucity of literature regarding childhood unintentional injuries in India, this study aims to estimate the burden and examine factors associated with unintentional injuries among children aged $1-5$ years residing in urban slums of Vellore city in Tamil Nadu, southern India. We have also attempted to assess the hazards posed by the living environment of these children and study their association with unintentional injury patterns.

\section{Methods}

This cross-sectional study was conducted between February to October 2013 in eight urban slums of Vellore city, Tamil Nadu, southern India and the period of data collection was from April through August 2013. The urban slums included Old town, Salavanpet, and neighboring areas with a population of around 13,000 with an average family size of 5.7 (3-13), population density of 42,000 per $\mathrm{km}^{2}$. Previous studies from similar urban slums in Vellore have reported an infant mortality rate of 38 per 1000 live births (John et al. 2014). Children between one and five years of age, with mothers being the primary caregiver and families residing in the study area for more than three months preceding the study were included. In case of more than one eligible child in the household, the youngest child was included. Children with primary caregivers other than mothers were excluded as previous studies show an association between children's risky behaviour, injury rate and mother's locus of control (Damashek et al. 2005). Assuming 50\% injury prevalence in the one to five years' age group and $10 \%$ relative precision at $95 \%$ confidence level, the calculated sample size was 384 (Hajian-Tilaki 2011; McGee et al. 2004). A door-to-door survey was conducted in the eight urban slums that identified 662 children in the study area who were satisfying our inclusion criteria and consenting to participate in the study. We decided to include all of the eligible children as a larger sample size would facilitate the evaluation of the Environmental Hazard Score (EHS). The study investigators (SLS and MSJ) have trained the field research assistants to administer the questionnaire, which was piloted in an urban slum that did not participate in the study and was modified based on feedback from piloting. Each primary caregiver was briefed about the study and trained field research assistants obtained written informed consents before administering the questionnaire (Additional file 1). The interview was held in the subjects' home at a time convenient for the mother, mostly in the mornings. The questionnaire captured details regarding family demographics and the details of injury, including frequency, type, location, and severity of injuries sustained by the 
children during a period of three months prior to the date of interview and written in the questionnaire forms; these forms were reviewed by the field supervisors on a daily basis and then sent for data entry. Injuries were classified according to the International Statistical Classification of Diseases and related Health problems 10th revision (ICD-10). The study was approved by Institutional Review Board (IRB) of Christian Medical College, Vellore (8078 dated 21.11.2012).

\section{Environmental hazard score (EHS)}

An indigenously developed Environmental hazard form (EHF) was used to assess the risk of different types of injuries such as falls, burns (thermal, chemical, and electric), road traffic injuries, poisoning, drowning, and mechanical hazards from household objects. For risk assessment, a base score (ranging from 0 to 4 ) was assigned based on the perceived severity for each type of injury mentioned above. A modifying factor score for each type of injury (0-4) was assigned based on the child's accessibility to the injury risk. The end hazard score for each injury type was calculated by multiplying the base score and the modifying factor score (For example, the base score for a child falling from roof is 4. The modifying factor score was based on accessibility. Scenario 1: If the child had no access to the roof the modifying score was 0 . Hence the overall score was $4 \times 0=0$. Scenario 2: However if the child had access to a roof without a parapet (modifier of 2) the score was $4 \times 2=8^{\prime \prime}$ ) (Additional file 2: Table S1). Sum of all the end scores from all the locations assessed gives the environmental hazard score for each individual. Environmental data were collected by the trained field research assistants for each child using the developed EHF at four common locations which included homes, play areas surrounding the home, schools and places where a child spent part of the average day (babysitter's home). The data were collected at all the four locations or only at locations applicable to each child according to his/her age. Finally, the total environmental hazard score (EHS) for each study child was calculated by taking the average of the hazard scores from all the available locations (Additional file 3 ). The environmental hazard risk was categorised as low risk ( $\leq 33$ centile), moderate risk (34-66 centiles) and high risk (> 66 centile).

\section{Definitions of injuries, outcome, and explanatory variables}

The primary outcome of the study was to assess the presence of UI in the children during the past three months from the date of data collection. Unintentional Injuries are defined as injuries occurring in short period of time with an unsought outcome and as a result of one of the forms of physical energy in the environment or normal body functions being blocked by external means (Christoffel et al. 1992). The operational definitions of different types of UI used in this study are as follows: fall as injury due to fall to the ground or fall on the ground; burns as injury that causes burns of any degree to the body tissue; electric burns as burn injury due to electrical and electronic gadgets; drowning as submerging in a body of water; poisoning as consumption of non edible substances, including chemicals; road traffic accidents as injury to any part of the body due to moving automobiles; heavy mechanical injury as injury due to a heavy object. Severe UI were defined as those UI requiring medical attention, that is, those that needed a visit to the hospital or treatment by a physician. Families with more than two persons living per room were defined as overcrowded dwellings. Modified kuppuswamy scale was used for assessing the socioeconomic status (Bairwa et al. 2013). Housing type was considered as "pucca" if houses were made with high quality materials throughout, including the floor, roof, and exterior walls and houses made from mud, thatch, or other low-quality materials were called kutcha houses (Ministry of Statistics and Programme Implementation, GOI 2013).

\section{Statistical analysis}

Double data entry was done using Epi-info software and data analyses were performed using STATA 13 software (StataCorp, College Station, TX, USA). The overall prevalence and incidence rates of UI per 100 child months with $95 \%$ confidence intervals were estimated based on injuries over a three month recall period which is three months prior to the date of interview. Bivariate analyses were performed to examine associations between socio-demographic factors and unintentional injuries among children. All socio-demographic factors with $p<0.2$ on bivariate analyses were included in a multivariable logistic regression model to examine the factors associated with unintentional injuries after adjusting for all the potentially confounding co-variates. Socio-demographic factors associated with repeated unintentional injuries were assessed using a Poisson regression model and over-dispersion was adjusted using a quasi-Poisson procedure. UI burden was estimated for children exposed to varying levels of environmental risk and a linear trend analysis was performed to examine association between environmental hazard risk categories and burden of UI.

\section{Results}

A total of 662 children were surveyed of which, $321(48.5 \%)$ were boys and 341(51.5\%) were girls. Majority, $611(92.3 \%)$ belonged to lower socioeconomic group and 356 (53.8\%) were Hindus. The median (IQR) family size was $5(4-7)$ and $361(55 \%)$ families had $\leq 2$ children in the house. Predominantly, 499 (75.4\%) families had $\leq 2$ rooms in the house and $273(41.3 \%)$ families lived in pucca houses. The mean (SD) years of schooling among mothers was $7.6(2.8)$ and 87 (13\%) mothers of study children had no formal schooling. The mean (SD) age of mothers was 26.4 (4.2) years and about 22\% (146/662) of them were gainfully employed (Table 1 ). 
Table 1 Baseline characteristics of study participants $(N=662)$

\begin{tabular}{|c|c|c|c|}
\hline Variables & Category & Frequency (n) & Percentage (\%) \\
\hline \multirow[t]{2}{*}{ Gender } & Male & 321 & 48.5 \\
\hline & Female & 341 & 51.5 \\
\hline \multirow{2}{*}{$\begin{array}{l}\text { Number of children } \\
\text { in the family }\end{array}$} & $\leq 2$ & 361 & 55.0 \\
\hline & $>2$ & 301 & 45.0 \\
\hline \multirow{2}{*}{$\begin{array}{l}\text { Number of adults } \\
\text { in the family }\end{array}$} & $\leq 2$ & 342 & 52.0 \\
\hline & $>2$ & 320 & 48.0 \\
\hline \multirow{2}{*}{$\begin{array}{l}\text { Number of siblings } \\
\text { for recruited child }\end{array}$} & $\leq 2$ & 578 & 87.3 \\
\hline & $>2$ & 84 & 12.7 \\
\hline \multirow[t]{3}{*}{ Religion } & Hindu & 356 & 53.8 \\
\hline & Christian & 16 & 2.4 \\
\hline & Muslim & 290 & 43.8 \\
\hline \multirow{2}{*}{$\begin{array}{l}\text { Maternal age } \\
\text { (years) }\end{array}$} & $\leq$ median 26 & 361 & 55.5 \\
\hline & > median 26 & 301 & 45.4 \\
\hline \multirow[t]{4}{*}{ Maternal education } & $\begin{array}{l}\text { No formal } \\
\text { education }\end{array}$ & 87 & 13 \\
\hline & Primary & 168 & 26 \\
\hline & High school & 339 & 51 \\
\hline & $\begin{array}{l}\text { Higher secondary/ } \\
\text { Graduate and } \\
\text { higher }\end{array}$ & 68 & 10 \\
\hline \multirow{2}{*}{$\begin{array}{l}\text { Maternal } \\
\text { occupation }\end{array}$} & Home maker & 516 & 78 \\
\hline & $\begin{array}{l}\text { Employed outside } \\
\text { home }\end{array}$ & 146 & 22 \\
\hline \multirow{2}{*}{$\begin{array}{l}\text { Father living with } \\
\text { the child }\end{array}$} & Yes & 637 & 96.2 \\
\hline & No & 25 & 3.8 \\
\hline \multirow[t]{2}{*}{ Paternal age (years) } & $\leq$ median 30 & 360 & 54.3 \\
\hline & >median 30 & 302 & 45.7 \\
\hline \multirow[t]{7}{*}{ Paternal education } & $\begin{array}{l}\text { Professional } \\
\text { degree }\end{array}$ & 4 & 0.6 \\
\hline & $\begin{array}{l}\text { Graduate/Post } \\
\text { graduate degree }\end{array}$ & 18 & 2.6 \\
\hline & $\begin{array}{l}\text { Post high school/ } \\
\text { diploma }\end{array}$ & 6 & 0.9 \\
\hline & $\begin{array}{l}\text { High school } \\
\text { certificate }\end{array}$ & 110 & 16.6 \\
\hline & $\begin{array}{l}\text { Middle school } \\
\text { certificate }\end{array}$ & 274 & 41.3 \\
\hline & $\begin{array}{l}\text { Primary school } \\
\text { certificate }\end{array}$ & 154 & 23.2 \\
\hline & No education & 96 & 14.5 \\
\hline \multirow{6}{*}{$\begin{array}{l}\text { Paternal } \\
\text { Occupation }\end{array}$} & Professional & 5 & 0.7 \\
\hline & Semi professional & 1 & 0.1 \\
\hline & $\begin{array}{l}\text { Clerical job/shop } \\
\text { owner/farmer }\end{array}$ & 21 & 3.1 \\
\hline & Skilled worker & 113 & 17.0 \\
\hline & $\begin{array}{l}\text { Semi-skilled } \\
\text { worker }\end{array}$ & 96 & 14.5 \\
\hline & Unskilled worker & 392 & 59.2 \\
\hline
\end{tabular}

Table 1 Baseline characteristics of study participants $(N=662)$ (Continued)

\begin{tabular}{llll}
\hline Variables & Category & Frequency (n) & Percentage (\%) \\
\hline \multirow{4}{*}{ Type of house } & Unemployed & 34 & 5.1 \\
& Pucca & 273 & 41.3 \\
& Semi pucca & 170 & 25.6 \\
& Kutcha & 219 & 33.1 \\
Family size & $\leq 5$ & 354 & 53.4 \\
& $>5$ & 308 & 46.6 \\
Number of rooms & $\leq 2$ & 499 & 75.4 \\
& $>2$ & 163 & 24.6 \\
Reported family & $<2000$ & 7 & 1 \\
income per & $2000-5000$ & 416 & 63 \\
month (INR) & $6000-10,000$ & 224 & 34 \\
& $>10,000$ & 15 & 2 \\
Socio-economic & Lower & 2 & 0.3 \\
status & Upper lower & 609 & 92.0 \\
& Lower middle & 46 & 7.0 \\
& Upper middle & 5 & 0.7 \\
\hline
\end{tabular}

\section{Burden of unintentional injuries}

The prevalence of UI among children aged 1-5 years was $39.1 \%$ (259/662, 95\% CI 35.4-42.9\%) over a three-month recall. The prevalence of UI was $42.6 \%$ (137/321) among boys and $35.8 \%$ (122/341) among girls and this difference was not statistically significant. Proportion of children sustaining UI in the age groups $13-24 ; 25-36 ; 37-48$ and 49-60 months were $33.7 \%$ (95\% CI 27.3-40.7); $40.3 \%$ (95\% CI 33.0-47.5); 40.9\% (95\% CI 33.5-48.6) and 43.1\% (95\% CI 35.0-52.0) respectively. Even though the proportion of children getting injured were increasing with age, this association was not statistically significant (Chi-square trend 2.76, P-value $=0.09)$ (Table 2).

Incidence rate of UI among the study children aged 1-5 years was 16.2 per 100 child months $(95 \%$ CI 14.6-18.1). Children in the age group of 4-5 years had a high risk of injury $(43.1 \%, 56 / 130)$ with an incidence rate of 17.4 (95\% CI 13.6-21.9) per 100 child months (Fig. 1). A total of 323 UI were reported in 259 children with $207(80 \%), 42(16.2 \%)$ and $10(3.8 \%)$ children experiencing one, two and more than two UI respectively. Among 323 UI, 306 (94.7\%) were due to falls, $9(2.7 \%)$ were due to burns/fire injuries and $5(1.5 \%)$ were due to road traffic injuries; injury type could not be determined for three injuries. Out of 306 fall injuries, 171(56\%) were among males, $135(44 \%)$ were among females and this difference was statistically significant $(P$-value $=0.04)$. However, there were no statistically significant gender differences in burns and road traffic injuries (Additional file 2: Table S2). Injuries due to drowning, electrocution or poisoning were not reported during the study period. 
Table 2 Age specific prevalence and incidence rates of unintentional injuries among study children aged 1-5 years

\begin{tabular}{|c|c|c|c|c|c|c|}
\hline $\begin{array}{l}\text { Age group } \\
\text { (Months) }\end{array}$ & $\begin{array}{l}\text { No. of } \\
\text { children }\end{array}$ & $\begin{array}{l}\text { No. of injured } \\
\text { children }\end{array}$ & $\begin{array}{l}\text { Proportion }^{a} \\
(95 \% \mathrm{Cl})\end{array}$ & Odds Ratio & $\begin{array}{l}\text { No. of } \\
\text { Injuries }\end{array}$ & $\begin{array}{l}\text { Incidence rate per } 100 \text { child } \\
\text { months }^{\mathrm{b}}(95 \% \mathrm{Cl})\end{array}$ \\
\hline $13-24$ & 187 & 63 & $33.7(27.3-40.7)$ & 1 & 83 & $14.8(11.8-18.2)$ \\
\hline $25-36$ & 186 & 75 & $40.3(33.5-47.5)$ & $1.33(0.85-2.07)$ & 91 & $16.3(13.2-19.9)$ \\
\hline $37-48$ & 159 & 65 & $40.9(33.5-48.6)$ & $1.36(0.85-2.16)$ & 81 & $16.9(13.6-21.0)$ \\
\hline $49-60$ & 130 & 56 & $43.1(35.0-52.0)$ & $1.48(0.91-2.42)$ & 68 & $17.4(13.6-21.9)$ \\
\hline Overall & 662 & 259 & $39.1(35.4-42.9)$ & & 323 & $16.2(14.6-18.1)$ \\
\hline
\end{tabular}

Linear trend analysis for proportion of unintentional injuries with age group $(P=0.09$, Chi square value $=2.76)$

${ }^{\mathrm{b}}$ Linear trend analysis for incidence rate with age group $(P$ value $=0.743$, Chi-square value $=1.27)$

\section{Factors associated with unintentional injuries}

Bivariate analyses revealed that children of working mothers have significantly higher odds (OR 1.48; 1.01-2.18) of sustaining unintentional injuries than children whose mothers stayed at home. Similarly, children from overcrowded families had significantly higher odds of having an unintentional injury (OR 1.78; 95\% CI 1.22-2.60). Other socio-demographic factors including presence of siblings, maternal age and education level; paternal age, education, occupation; family size and income were not significantly associated with higher risk of unintentional injuries (Table 3). Multivariate logistic regression analysis showed that children residing in overcrowded families (AOR 1.66; 95\% CI 1.14-2.41) were significantly at higher odds of getting injured after adjusting for gender, presence of siblings, maternal occupation, type of house and overcrowding (Table 3).

\section{Factors associated with repeated unintentional injuries}

Any child sustaining more than one unintentional injury during the three-month recall period was considered to have repeated UI. Poisson regression analysis for assessing the risk of having repeated UI has revealed that, children from overcrowded families experienced higher risk of repeated unintentional injuries (IRR 1.50; 95\% CI 1.14-1.98) after adjusting for age, gender, presence of siblings, maternal occupation, housing type and overcrowding. Boys had significantly increased risk of having repeated injury compared to girls (IRR 1.33, 95\% CI 1.07-1.66). Older children (age $>2$ years), the presence of siblings, working mothers, and poor housing conditions had higher risk of repeated UI but not at statistically significant level (Table 4).

\section{Environmental hazard risk and association with unintentional injuries}

The mean (SD) of total environmental hazard score (EHS) was 24.3(14.5). The highest hazard score was present at babysitter/caregivers home 28.6(12.3) followed by homes of children 28.1(16.8). Play areas had a hazard score of 23.1(13.2) and least hazardous were schools with a score of 18.8(9.7). Based on the 33rd and 66th percentiles of the total EHS, children exposed to areas with scores less than or equal to 18.3 were considered to be at low risk, between 18.4 and 28.5 to be at moderate risk and more than 28.5 to be at high environmental risk for sustaining injuries. Among all the study children,

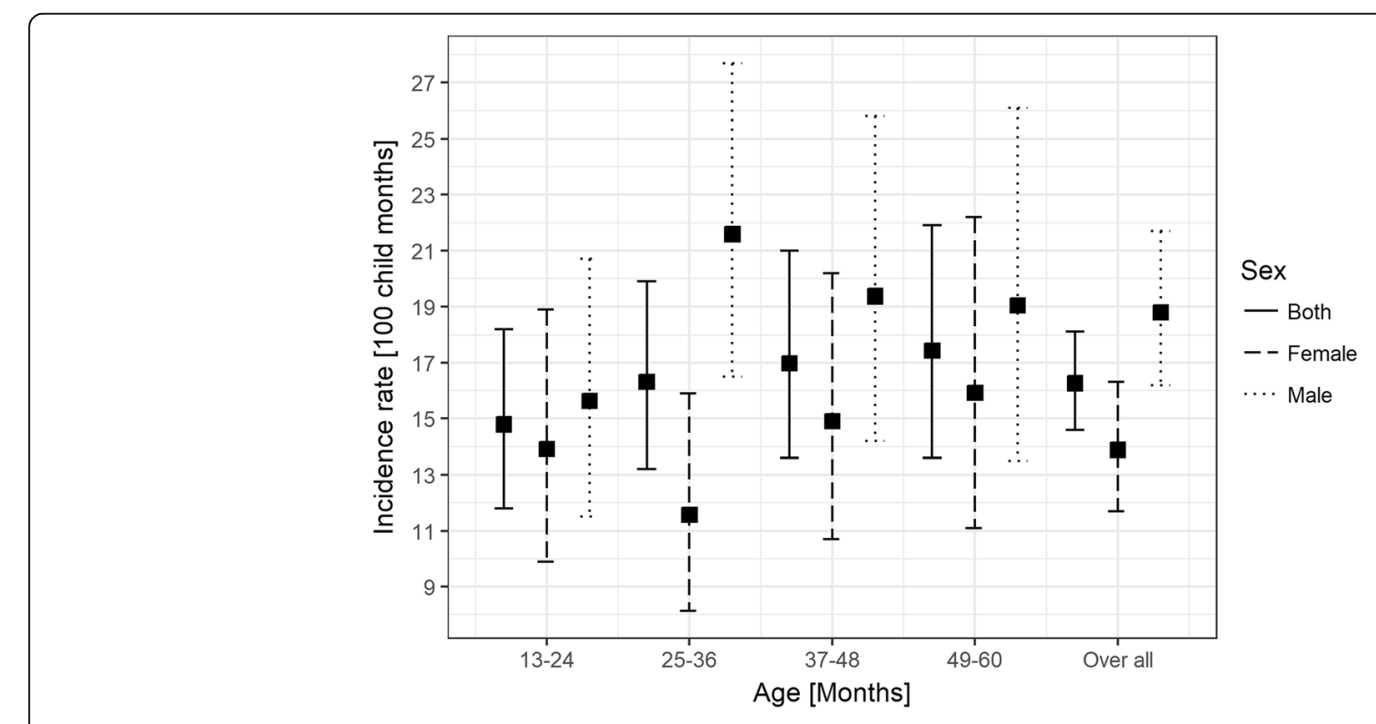

Fig. 1 Gender specific incidence rates of unintentional injuries among children of 1-5 years 
Table 3 Association between socio-demographic factors and unintentional injuries in the study

\begin{tabular}{|c|c|c|c|c|c|}
\hline Co-variates & Cateogery & $\begin{array}{l}\text { Injured in past } \\
3 \text { months }\end{array}$ & $\begin{array}{l}\text { Uninjured in past } \\
3 \text { months }\end{array}$ & $\begin{array}{l}\text { Unadjusted OR } \\
(95 \% \mathrm{Cl})\end{array}$ & $\begin{array}{l}\text { Adjusted } \mathrm{OR}^{\mathrm{b}} \\
(95 \% \mathrm{Cl})\end{array}$ \\
\hline \multirow[t]{2}{*}{ Gender } & Male & $137(42.6 \%)$ & $184(57.4 \%)$ & $1.34(0.97-1.85)$ & $1.31(0.96-1.81)$ \\
\hline & Female & $122(35.8 \%)$ & $219(64.2 \%)$ & & \\
\hline \multirow[t]{2}{*}{ Siblings } & $\leq 2$ & $221(38 \%)$ & $357(62 \%)$ & $0.74(0.46-1.22)$ & $1.11(0.69-1.79)$ \\
\hline & $>2$ & $38(45 \%)$ & $46(55 \%)$ & & \\
\hline \multirow[t]{2}{*}{ Maternal age } & $\leq$ median & $145(40.1 \%)$ & $216(59.9 \%)$ & $1.10(0.79-1.52)$ & \\
\hline & $>$ median & $114(37.9 \%)$ & $187(62.1 \%)$ & & \\
\hline \multirow[t]{2}{*}{ Maternal education } & $0-7$ yrs & $142(41.3 \%)$ & $202(58.7 \%)$ & $1.20(0.87-1.67)$ & \\
\hline & $\geq 8$ yrs & $117(36.8 \%)$ & $201(63.2 \%)$ & & \\
\hline \multirow[t]{2}{*}{ Maternal occupation } & Home maker & $68(46.6 \%)$ & $78(53.4 \%)$ & $1.48(1.01-2.18)$ & $1.34(0.92-1.97)$ \\
\hline & Employed outside home & 191(37.1\%) & $325(62.9 \%)$ & & \\
\hline \multirow[t]{2}{*}{ Father living with the child } & Yes & $250(39.2 \%)$ & $387(60.7 \%)$ & $1.14(0.47-3)$ & \\
\hline & No & $9(36 \%)$ & $16(64 \%)$ & & \\
\hline \multirow[t]{2}{*}{ Paternal age } & $\leq$ median & $110(36.4 \%)$ & $192(63.6 \%)$ & $0.81(0.58-1.12)$ & \\
\hline & $>$ median & 149(41.4\%) & $211(58.6 \%)$ & & \\
\hline \multirow[t]{2}{*}{ Paternal Education } & $0-7$ yrs & 160(39.7\%) & $243(60.3 \%)$ & $1.06(0.73-1.48)$ & \\
\hline & $\geq 8$ yrs & 99(38.2\%) & $160(61.8 \%)$ & & \\
\hline \multirow[t]{2}{*}{ Paternal occupation } & Unemployed & $15(44.1 \%)$ & 19(55.9\%) & $1.24(0.57-2.63)$ & \\
\hline & working & $244(38.8 \%)$ & $384(61.2 \%)$ & & \\
\hline \multirow[t]{2}{*}{ House Type } & Others & $163(42 \%)$ & $226(58 \%)$ & $1.32(0.95-1.85)$ & $1.16(0.83-1.61)$ \\
\hline & Pucca & $96(35 \%)$ & $177(65 \%)$ & & \\
\hline \multirow[t]{2}{*}{ Family size } & $\leq 5$ & 137(38.7\%) & $217(61.3 \%)$ & $0.96(0.69-1.33)$ & \\
\hline & $>5$ & $122(40 \%)$ & $186(60 \%)$ & & \\
\hline \multirow[t]{2}{*}{ Number of rooms } & $\leq 2$ & $205(41 \%)$ & 294(59\%) & $1.40(0.95-2.1)$ & \\
\hline & $>2$ & $54(33 \%)$ & 109(67\%) & & \\
\hline \multirow[t]{2}{*}{ Over crowding } & $>2$ per room & $202(43 \%)$ & $268(57 \%)$ & $1.78(1.22-2.6)$ & $1.66(1.14-2.41)$ \\
\hline & $\leq 2$ per room & $57(30 \%)$ & 135(70\%) & & \\
\hline \multirow[t]{2}{*}{ Family income per month (INR) } & $<4650$ & $137(41 \%)$ & 198(59\%) & $1.16(0.84-1.6)$ & \\
\hline & 4650 or more & $122(37.3 \%)$ & $205(62.7 \%)$ & & \\
\hline
\end{tabular}

Bivariate analysis

${ }^{\mathrm{b}}$ Multivariable logistic regression analysis

Table 4 Factors associated with repeated unintentional injuries using Poisson regression analysis

\begin{tabular}{lll}
\hline Variable & $\begin{array}{l}\text { Unadjusted } \\
\text { IRR }\end{array}$ & $\begin{array}{l}\text { Adjusted } \\
\text { IRR }(95 \% \mathrm{Cl})\end{array}$ \\
\hline Age $>$ 2 years & 1.11 & $1.11(0.87-1.44)$ \\
Male & $1.35^{\mathrm{a}}$ & $1.33^{\mathrm{a}}(1.07-1.66)$ \\
Siblings & 1.20 & $1.06(0.77-1.43)$ \\
Mother employed outside home & 1.26 & $1.18(0.92-1.51)$ \\
Type of house (Semi pucca/Kutcha) & 1.15 & $1.04(0.83-1.31)$ \\
Overcrowding $>$ 2 persons/room & $1.56^{\mathrm{a}}$ & $1.50^{\mathrm{a}}(1.14-1.98)$ \\
\hline
\end{tabular}

${ }^{a}$ Statistically significant with a $P$ value $<0.05$
209(32\%) were exposed to low-environmental risk, $218(33.5 \%)$ to moderate- and 225(34.5\%) children to high environmental risk. The proportions of children sustaining UI were $35.8 \%, 39.5 \%$ and $42.3 \%$ in the low, moderate and high environmental risk categories and this rising trend was not statistically significant (Table 5). The incidence rates of UI were $14.8(95 \%$ CI $12.0-18.0$ ), 16.1 (95\% CI 13.2-19.6) and $18.6(95 \%$ CI 15.6-22.1) among children exposed to low, moderate and high environmental risk. Similarly, the incidence rates of severe UI were 6.4 (95\% CI 4.6-8.6), 6.3 (95\% CI 4.5-8.4) and 6.5 (95\% CI 4.8-8.7) among children exposed to low, moderate and high environmental risk. These increasing rates with increasing environmental exposures were not statistically significant (Table 5). 
Table 5 Environmental hazard risk and injury rates among the study children

\begin{tabular}{llllll}
\hline $\begin{array}{l}\text { Environmental } \\
\text { hazard risk }\end{array}$ & $\begin{array}{l}\text { Number of } \\
\text { study children }(\mathrm{N})\end{array}$ & $\begin{array}{l}\text { No of children } \\
\text { injured }^{\mathrm{n}}(\%, 95 \% \mathrm{Cl})\end{array}$ & $\begin{array}{l}\text { Incidence rate of injuries per } \\
100 \text { child months }^{\mathrm{b}}(95 \% \mathrm{Cl})\end{array}$ & $\begin{array}{l}\text { No of children severely } \\
\text { injured } \mathrm{n}(\%, 95 \% \mathrm{Cl})\end{array}$ & $\begin{array}{l}\text { Incidence rate of severe injuries } \\
\text { per } 100 \text { child months }^{\mathrm{d}}(95 \% \mathrm{Cl})\end{array}$ \\
\hline Low $(\leq 18.3)$ & 209 & $75(35.8,28.4-42.8)$ & $14.8(12.0-18.0)$ & $38(18.2,13.4-23.8)$ & $6.4(4.6-8.6)$ \\
$\begin{array}{l}\text { Moderate } \\
(18.4-28.5)\end{array}$ & 218 & $86(39.5,32.9-46.3)$ & $16.1(13.25-19.5)$ & $37(17.0,12.2-22.6)$ & $6.3(4.5-8.4)$ \\
High $(>28.5)$ & 225 & $95(42.3,35.7-48.9)$ & $18.6(15.6-22.1)$ & $39(17.3,12.8-22.7)$ & $6.5(4.8-8.7)$ \\
Total & 652 & $256(39.3,35.5-43.1)$ & $16.5(14.7-18.3)$ & $114(17.4,14.7-20.5)$ & $6.4(5.3-7.6)$
\end{tabular}

${ }^{\mathrm{a}}$ Linear trend analysis for number of injured children as per environmental hazard risk cateogeries $(P=0.17$, Chi square $=1.81)$

${ }^{b}$ Linear trend analysis for incidence rate of injury as per environmental hazard risk cateogeries $(P=0.18$, Chi square value $=3.36)$

${ }^{\mathrm{C}}$ Linear trend analysis for number of severely injured children as per environmental hazard risk cateogeries $(P=0.77$, Chi square $=0.08)$

dLinear trend analysis for incidence rate for severe injury as per environmental hazard risk cateogeries $(P=0.98, C h i$ square value $=0.04)$

\section{Discussion}

The prevalence of UI among children aged 1-5 years residing in urban slums of Vellore was $39.1 \%$ which is much higher compared to $8.5 \%$ among children of $0-5$ years residing in urban slums of New Delhi (Parmeswaran et al. 2017). Higher injury risk were also seen among the urban slum residents in Chennai and in squatter settlements in Karachi, Pakistan which is now corroborated by our study (Rizvi et al. 2006; Sathiyasekaran 1996). Unintentional injuries in this age group are affected by a combination of various environmental and psychological factors. Particularly in young children, the innate curiosity and desire to experiment are not always matched with the ability to understand or respond to danger. The drive to play can override the need for caution even when an appropriate understanding of danger and ability to respond has been attained by developmental maturity (Bartlett 2002). Additionally, as the child passes through this age group, parents increasingly rely on behavioral modification and their trust in the child's awareness of environment as the primary preventive measure, as opposed to environmental modification (Morrongiello et al. 2004a). It was also seen that preschoolers over the age of 2.5 years were at higher risk of UI than younger toddlers (Dal Santo et al. 2004).

Overcrowding was a significant risk factor for overall UI rate and also for risk of repeated UI. This finding is worrying considering that urban slums continue to grow and get more crowded every day leading to consequent lack of space in Indian towns and cities (Bandyopadhyay and Agrawal 2013). Socio-demographic factors that affect housing and living conditions in these slums could influence hazard and injury patterns. In our study, we did not find any electrocution related UI but a study from Surat, Gujarat has documented that rates of electrocution from electric sockets were increased among the families of high socioeconomic status, most likely as a result of access to electricity (Chaudhari et al. 2009). The same study also found a relation between precautionary measures and the mothers' level of education which is a limitation of our study as we did not look for precautionary measures. The UI rates were higher in children with working mothers but there was no increase in the frequency of injuries that required medical attention. Whether there is an actual issue with supervision or if there are psychological factors associated with mothers being forced to leave their children at home and over-reporting injuries compared to their stay-at-home peers remains to be studied in this area. Socio-economic factors have also been shown to affect UI-related death rates in other studies but we did not find any significant relationship between any socioeconomic factors within this community and risk of UI (Hong et al. 2010; Laursen et al. 2008). Demographic factors such as the age of the parents and whether the child lives in a single parent or divorced household, or with both parents have also been implicated as determinants of childhood UI but were not found to be significant in our study (Dudani et al. 2010; Hong et al. 2010).

Consequently, as a step towards identifying the interaction of environmental hazards with these children, a hazard scoring was done not only for each child's residence but also for their play areas, babysitters' houses and schools as applicable. For example, play areas that were not cordoned off pose a risk of the child running into traffic, homes that did not have parapets to child accessible roofs posed a higher risk of falls to the ground and open fires or stoves on the ground posed risks of the child getting burned. It has been reported that in a high-risk environment (high EHS), even when the perception of hazard risk is high and maternal supervision is high, the rate of UI remains high (Dal Santo et al. 2004). The higher environmental hazard scores were associated with higher rates of UI and severe UI. Housing other than a pucca house has been shown to influence UI rates and combined with the fact that most UI in young children occur in and around homes it is imperative that necessary interventions be placed in these areas to prevent further injury (Dal Santo et al. 2004; Reading et al. 1999). Behavioral and socio-demographic factors are extremely important in understanding these UI and to attain a 'holistic' approach to a possible intervention. This outlines the importance of the identification and elimination of environmental hazards as a first line intervention in reducing the rate of childhood UI; and the 
urgent need for the same is highlighted by our results showing an increase in incidence rate of UI with an increase in the environmental hazard risk although not at a statistically significant level. Possible reason for not having statistically significant difference of incidence rates with increase of environmental hazard risk could be the smaller sample size. The EHS system designed in this study can be easily used to assess environmental risk across a broader spectrum of areas frequently accessed by children after validating it with a larger sample size.

Parental behavior is another important determinant of UI risk. Although it was beyond the scope of our study, it is important to determine if parents will be willing to implement any intervention and also determine if those interventions will be helpful in reducing the hazards (Dal Santo et al. 2004; Damashek et al. 2005; Dudani et al. 2010; Glik et al. 1991; Hong et al. 2010; Morrongiello et al. 2004b; Russell and Champion 1996). Various factors such as maternal anxiety, maternal stress levels and age of the parents determine childhood injury rates (Hong et al. 2010; Morrongiello et al. 2004b). Mothers who believe that their child getting hurt is not controlled by them, i.e., who have an external locus of control have also been found to have higher UI rates in their children (Damashek et al. 2005). Parental risk perceptions also interact with all the previously outlined factors in determining injury risk and are affected by various socio-cultural factors (Dal Santo et al. 2004; Damashek et al. 2005; Glik et al. 1991; Morrongiello et al. 2004a). For example, having a child recently injured alters the parent's perception of how dangerous the environment is and this, in turn, may affect the strategies undertaken to prevent further such incidents (Glik et al. 1991; Russell and Champion 1996). A community's perception of the health problem also has a large role to play in what interventions may be implemented and research in Africa has shown that interventions that are passive, rather than those requiring greater parental effort, are more likely to be welcomed by the community (Larsson et al. 2006; Munro et al. 2006; Ruiz-Casares 2009). Therefore, an appropriate understanding of the parents' and community's ideas surrounding childhood unintentional injuries is essential to design any intervention. An interesting new finding in this study is boys had an increased risk of repeated UI. To understand this, further studies on socio-cultural factors and behavioral patterns of children and parents are needed.

It is clear that childhood unintentional injuries are the product of a complex interaction between human behavior (that of the parent and child), the environment they live in and various socio-demographic factors; all these factors are interrelated and influence each other (Glik et al. 1991; Larsson et al. 2006; Munro et al. 2006; Ruiz-Casares 2009; Russell and Champion 1996). However in this study area, with the findings of high rates of UI in a hazard intense environment, it is imperative that provision of safe play environments by reducing the environmental hazards be implemented first and a further behavioral study will only be secondary to the same.

\section{Limitations}

One of the limitations of the study is that children with primary caregivers other than mothers were excluded. Recall bias was a known limitation of the study, which was attempted to overcome by asking how the injury was treated; this allowed mothers to recall the actual event. Interviewer bias was another limitation, although the field research assistants used the same words in each interview and the questionnaire forms crosschecked and verified on a daily basis, they were not auto validated.

\section{Conclusions}

The burden of unintentional injuries was very high among study children when compared to studies in other urban slums. Provision of safe environments and supervision of children is needed to prevent UI considering the high burden in the study population. The indigenously developed environmental hazard score (EHS) could possibly be used as a tool to assess the risk of UI at homes and other places frequently visited by children, after it has been validated with a larger sample size. Recent initiative by the Government of India for building smart cities with planned urbanization should be addressing the environmental hazards posed to the communities. However, policy decisions for community-based interventions with combined engineering, environmental measures need to be implemented to reduce the environmental hazards to children while further research is recommended to ascertain the behavioral and psychological components.

\section{Additional files}

Additional file 1: Questionnaire for childhood injuries (DOCX $21 \mathrm{~kb}$ )

Additional file 2: Table S1. Example of calculating environmental hazard score for a subject at one location. Table S2. Distribution of different types of injuries as per gender (DOCX $14 \mathrm{~kb}$ )

Additional file 3: Environmental Hazard Observation Form (DOCX $22 \mathrm{~kb}$ )

\begin{abstract}
Abbreviations
Cl: Confidence interval; EHF: Environmental hazard form; EHS: Environmental hazard score; ICD-10-CM: International Classification of Diseases, Tenth Revision, Clinical Modification; IQR: Interquartile range; IRR: Incidence rate ratio; OR: Odds ratio; SD: Standard deviation; SES: Socioeconomic status; UI: Unintentional injuries; WHO: World health organization
\end{abstract}

\section{Acknowledgments}

The authors would like to thank all the participating mothers and field research assistants for their help in this project. 


\section{Funding}

The study was funded by an internal fluid research grant from Christian Medical College, Vellore.

\section{Availability of data and materials}

Anonymous datasets and materials are available upon request.

\section{Authors' contributions}

SLS, MSJ developed the idea and $A R, A B, S M J$ and VRM helped with the methodology of the study. SLS, MSJ, AR, AB and VRM acquired the funding and conducted the study. SLS, SR, MSJ and VRM conceived the idea of the paper. KR and SR performed the analysis and interpreted the results. SR, SLS and MSJ prepared the manuscript and VRM edited the manuscript prior to submission. All authors read and approved the final manuscript.

\section{Ethics approval and consent to participate}

This study was reviewed and approved by the Institutional Review Board (IRB) of Christian Medical College, Vellore (8078 dated 21.11.2012). All the participants provided informed consent.

\section{Consent for publication}

All the participants provided consent for publication.

\section{Competing interests}

The authors declare that they have no competing interests.

\section{Publisher's Note}

Springer Nature remains neutral with regard to jurisdictional claims in published maps and institutional affiliations.

\section{Author details}

${ }^{1}$ Department of General Surgery, Christian Medical College, Vellore, Tamil Nadu 632004, India. ${ }^{2}$ The Wellcome Trust Research Laboratory, Division of Gastrointestinal sciences, Christian Medical College, Vellore, Tamil Nadu 632004, India. ${ }^{3}$ Department of Community Health, Christian Medical College, Vellore, Tamil Nadu 632004, India. ${ }^{4}$ Low Cost Effective Care Unit, Christian Medical College, Vellore, Tamil Nadu 632001, India.

Received: 7 June 2018 Accepted: 9 October 2018

\section{Published online: 05 November 2018}

\section{References}

Bairwa M, Rajput M, Sachdeva S. Modified Kuppuswamy's socioeconomic scale: social researcher should include updated income criteria, 2012. Indian J Community Med. 2013:38(3):185-6.

Bandyopadhyay DA, Agrawal V. Slums in India: from past to present. Int Refereed J Eng Sci IRJES. 2013;2(4):55-9.

Bartlett $\mathrm{S}$. The problem of children's injuries in low income countries: a review. Health Policy Plan. 2002:17:1-13.

Borse NN, Gilchrist J, Dellinger AM, Rudd RA, Ballesteros MF, Sleet DA. Patterns of unintentional injuries among 0-19 year olds in the United States. 2008;

Chandran A, Hyder A, Peek-Asa C. The global burden of unintentional injuries and an agenda for progress. Epidemiol Rev. 2010;32(1):110-20.

Chaudhari V, Srivastava R, Moitra M, Desai V. Risk of domestic accidents among under five children. Internet J Fam Pract. 2009;7:1.

Christoffel KK, Scheidt PC, Agran PF, Kraus JF, McLoughlin E, Paulson JA. Standard definitions for childhood injury research: excerpts of a conference report. Pediatrics. 1992 Jun 1:89(6):1027-34.

Dal Santo JA, Goodman RM, Glik D, Jackson K. Childhood unintentional injuries: factors predicting injury risk among preschoolers. J Pediatr Psychol. 2004; 29(4):273-83.

Damashek A, Williams N, Sher K, Peterson L, Lewis T, Schweinle W, et al. Risk for minor childhood injury: an investigation of maternal and child factors. Psychol Sep Epub Mar 3. 2005;30(6 SRC-GoogleScholar):469-480.

Dudani A, Macpherson A, Tamim H. Childhood behavior problems and unintentional injury: a longitudinal, population-based study. J Behav Pediatr May. 2010;31(4 SRC-GoogleScholar):276-285.

Fadel SA, Rasaily R, Awasthi S, Begum R, Black RE, Gelband H, et al. Changes in cause-specific neonatal and 1-59-month child mortality in India from 2000 to 2015: a nationally representative survey. Lancet. 2017;390(10106):1972-80.
Glik D, Kronenfeld J, Jackson K. Predictors of risk perceptions of childhood injury among parents of preschoolers. Health Educ Q Fall. 1991;18(3 SRCGoogleScholar):285-301.

Global Burden of Disease Child and Adolescent Health Collaboration, Kassebaum N, Kyu HH, Zoeckler L, Olsen HE, Thomas K, et al. Child and Adolescent Health From 1990 to 2015: Findings From the Global Burden of Diseases, Injuries, and Risk Factors 2015 Study. JAMA Pediatr. 2017 Jun 1;171(6):573-92.

Hajian-Tilaki K. Sample size estimation in epidemiologic studies. Casp J Intern Med. 2011:2(4):289-98.

Hong J, Lee B, Ha EH, Park H. Parental socioeconomic status and unintentional injury deaths in early childhood: consideration of injury mechanisms, age at death, and gender. Accid Anal Prev. 2010;42(1):313-9.

Hyder AA, Sugerman DE, Puvanachandra P, Razzak J, El-Sayed H, Isaza A, et al. Global childhood unintentional injury surveillance in four cities in developing countries: a pilot study. Bull World Health Organ. 2009;87(5):345-52.

Imamura J, Troster E, Oliveira C. What types of unintentional injuries kill our children? Do infants die of the same types of injuries? A systematic review. Clin Sao Paulo Sep. 2012;67(9 SRC-GoogleScholar):1107-1116.

Jagnoor J, Bassani DG, Keay L, Ivers RQ, Thakur JS, Gururaj G, et al. Unintentional injury deaths among children younger than 5 years of age in India: a nationally representative study. Inj Prevention. 2011;17(3):151-5.

John SM, Thomas RJ, Kaki S, Sharma SL, Ramanujam K, Raghava MV, et al. Establishment of the MAL-ED birth cohort study site in Vellore, Southern India. Clin Infect Dis. 2014 Nov 1;59(Suppl 4):S295-9.

Larsson L, Butterfield P, Christopher S, Hill W. Rural community leaders' perceptions of environmental health risks: improving community health. AAOHN J Mar. 2006;54(3 SRC-GoogleScholar):105-112.

Laursen B, Nielsen J. Influence of sociodemographic factors on the risk of unintentional childhood home injuries. Eur J Health Aug Epub May 31. 2008; 18(4 SRC-GoogleScholar):366-370.

McGee K, Sethi D, Peden M, Habibula S. Guidelines for conducting community surveys on injuries and violence. Int J Inj Control Saf Promot. 2004;11(4):303-6.

Ministry of Statistics and Programme Implementation, GOI. Housing Condition and household amenities. Stat. Year b. India 2013 [Internet]. The government of India; 2013 [cited 2018 Oct 13]. p. 28. Available from: http://mospi.nic.in/ sites/default/files/Statistical_year_book_india_chapters/HOUSING\%20\%20WRITEUP.pdf.

Morrongiello BA, Matheis S. Understanding Children's injury-risk behaviors: the independent contributions of cognitions and emotions. J Pediatr Psychol. 2007;32(8):926-37.

Morrongiello BA, Ondejko L, Littlejohn A. Understanding toddlers' in-home injuries: II. Examining parental strategies, and their efficacy, for managing child injury risk. J Pediatr Psychol. 2004a;29(6):433-46.

Morrongiello BA, Ondejko L, Littlejohn A. Understanding toddlers' in-home injuries: I. context, correlates, and determinants. J Pediatr Psychol. 2004b; 29(6):415-31

Munro S, van Niekerk A, Seedat M. Childhood unintentional injuries: the perceived impact of the environment, lack of supervision and child characteristics. Child Care Health Dev May. 2006;32(3 SRC-GoogleScholar):269-279.

Naeini HS, Lindqvist K, Jafari HR, Mirlohi AH, Dalal K. Playground injuries in children. Open Access J Sports Med. 2011;2:61-8.

Nambiar D, Razzak J, Afsana K, Adams AM, Hasan A, Mohan D, et al. Mental illness and injuries: emerging health challenges of urbanisation in South Asia. BMJ. 2017;357:j1126.

Nirgude AS, Naik PR, Sheikh NA. Pattern of Childhood Injuries in a Rural Area of South India. Indian J Forensic Med Toxicol. 2012;6:1.

Parmeswaran GG, Kalaivani M, Gupta SK, Goswami AK, Nongkynrih B. Unintentional childhood injuries in urban Delhi: a community-based study. Indian J Community Med. 2017;42(1):8-12.

Peden M, Oyegbite K, Ozanne-Smith J, Hyder AA, Branche C, Rahman AF, et al., editors. World Report on Child Injury Prevention [Internet]. Geneva: World Health Organization; 2008 [cited 2018 Jun 2]. Available from: http://www. ncbi.nlm.nih.gov/books/NBK310641/

Reading R, Langford I, Haynes R, Lovett A. Accidents in preschool children: Comparing family and neighborhood risk factors. Soc Sci Med. 1999;48(3 SRC-GoogleScholar):321-30.

Rizvi N, Luby S, Azam SI, Rabbani F. Distribution and circumstances of injuries in squatter settlements of Karachi. Pakistan Accid Anal Prev. 2006;38(3):526-31.

Ruiz-Casares M. Unintentional childhood injuries in sub-Saharan Africa: an overview of risk and protective factors. J Care Poor Underserved. 2009:20(4 Suppl SRC-GoogleScholar):51-67. 
Russell KM, Champion VL. Health beliefs and social influence in home safety practices of mothers with preschool children. Image J Nurs Sch. 1996; 28(1):59-64.

Sathiyasekaran BW. Population-based cohort study of injuries. Injury. 1996; 27(10):695-8.

Sivamani M, Balraj V, Muliyil J. Validity of a surveillance system for childhood injuries in a rural block of tamilnadu. Indian J Community Med. 2009; 34(1):43-7.

Sminkey L. World report on child injury prevention. Inj Prev. 2008;14(1):69

Tripathi S. Determinants of large City slum incidence in India: a cross-sectional study. Poverty Public Policy. 2015;7(1):22-43.

WHO. World Health Statistics 2015 [Internet]. World Health Organization; 2015 p. 164. Available from: http://apps.who.int/iris/bitstream/handle/10665/170250/ 9789240694439_eng.pdf?sequence $=1$

\section{Submit your manuscript to a SpringerOpen ${ }^{\circ}$ journal and benefit from:}

- Convenient online submission

- Rigorous peer review

- Open access: articles freely available online

- High visibility within the field

- Retaining the copyright to your article

Submit your next manuscript at $\boldsymbol{\nabla}$ springeropen.com 